\title{
Cardiovascular health and cognitive function among Mexican older adults: cross-sectional results from the WHO Study on Global Ageing and Adult Health
}

\author{
Jaime Perales, ${ }^{1}$ Ladson Hinton, ${ }^{2}$ Jeffrey Burns ${ }^{1}$ and Eric D. Vidoni ${ }^{1}$ \\ ${ }^{1}$ Department of Neurology, University of Kansas Alzheimer's Disease Center, Fairway, Kansas, USA \\ ${ }^{2}$ Department of Psychiatry and Behavioral Sciences, University of California, Davis, California, USA
}

ABSTRACT

Objectives: To assess the association between cardiovascular health and cognitive function among Mexican older adults.

Design: Nationally representative cross-sectional survey.

Setting: Households in Mexico.

Participants: Individuals aged 50 years and older $(n=1,492)$ from the Mexico-SAGE project Wave 1.

Measurements: A continuous and a categorical index of cardiovascular health was calculated based on exercise, smoking, body mass index, and blood pressure ranging from 0 to 4 . Cognitive function was obtained by averaging the standardized scores ( $z$ scores) of five psychometric tests. Associations were conducted using linear regression.

Results: The continuous index of cardiovascular health was not associated with cognitive function. Using the categorical index, participants with the best levels of cardiovascular (score of 4) health performed better on global cognitive function than groups with lower cardiovascular health (scores of $0,0.41 S D ; 1,0.39 S D$; and $2,0.56 S D$ ). The association was moderated by age, reaching significance only among those 50-64 years old.

Conclusions: If longitudinal research confirms these findings, results would suggest that dementia-related policies in Mexico need to focus on achieving optimal levels of cardiovascular health, especially in midlife.

Key words: cognitive activity, dementia, aging

\section{Introduction}

Dementia and cognitive decline are among the greatest public health challenges Mexico will face in the coming years. Mexico's population has quickly aged in the last decades. Mexicans 60 years and older will represent one in every five people by 2030 (Instituto Nacional de Salud Pública [INSP], 2014). Meanwhile, the average life expectancy, currently 77 , continues to increase to a projected 80 by 2050 (Instituto Nacional de Salud Pública [INSP], 2014; World Health Organization, 2015). This population shift has led to one of the highest rates of dementia in the Americas, currently 30.4 per 1,000 person-years among Mexicans 65

Correspondence should be addressed to: Eric D. Vidoni, Department of Neurology, University of Kansas Alzheimer's Disease Center, MS6002, Fairway, Kansas 66205, USA. Phone: +1-913-588-5312. Email: evidoni@kumc.edu. Received 6 Jan 2018; revision requested 28 Jan 2018; revised version received 8 Feb 2018; accepted 13 Feb 2018. First published online 18 April 2018. years and older (Prince et al., 2013). A better understanding of brain health is needed to reduce the health and financial impact of dementia on individuals, families, and societies (World Health Organization, 2012).

Studies such as the Mexican Health and Aging study show that individual cardiovascular risk factors are associated with cognitive decline and dementia (Mejía-Arango et al., 2007; Mejia-Arango and Gutierrez, 2011; Silvia and Clemente, 2011). Cardiovascular risk indices have been associated with cognition among Mexican Americans in the Sacramento Area Latino Study on Aging study and other populations (Yaffe et al., 2007; Unverzagt et al., 2011; Al Hazzouri et al., 2013). Health indices of factors that coexist and have a common pathway are promising as they are more comprehensive than single factors (Pearson et al., 2013). However, prevention strategies need to also focus on optimal levels of modifiable health to increase population impact rather than merely on poor levels (Lloyd-Jones et al., 2010). 
The American Heart Association (AHA) defined a cardiovascular health $(\mathrm{CVH})$ index to track health status in relation to their 2020 strategic goal (Lloyd-Jones et al., 2010). This concept includes a set of modifiable cardiovascular risk factors and health behaviors graded either poor, intermediate, or ideal. The AHA's CVH index has been shown to be associated with lower incidence of stroke, cardiovascular disease, and related mortality (Dong et al., 2012; Kulshreshtha et al., 2013). A few studies in the USA have found associations between the AHA's CVH index and cognitive outcomes among people of different ethnic backgrounds (Reis et al., 2013; Crichton et al., 2014; Thacker et al., 2014; Gardener et al., 2016; González et al., 2016). For example, one cross-sectional study found positive associations between $\mathrm{CVH}$ and scores of cognitive status, verbal learning, phonemic word fluency, and processing speed among USA middleaged Latinos (González et al., 2016). The Northern Manhattan Study found that in a sample with $65 \%$ of mostly Caribbean Latinos, the higher number of ideal $\mathrm{CVH}$ metrics was associated with less decline in different cognitive domains (Gardener et al., 2016).

Determining the association between $\mathrm{CVH}$ and cognitive function in Mexico is important to promote dementia and cognitive decline prevention and healthy brain aging in this country. Mexico has not just one of the highest rates of dementia in the Americas but also the highest prevalence of diabetes (Shaw et al., 2010), obesity (World Obesity Federation, 2017), and hypertension (Ordúñez et al., 2001). Therefore, the aim of this study is to explore the association between an index of ideal levels of modifiable $\mathrm{CVH}$ factors and cognitive function among Mexican older adults using nationally representative cross-sectional data. We hypothesize that better levels of $\mathrm{CVH}$ will be associated with higher cognitive function. Previous research shows that some $\mathrm{CVH}$ components including body mass index (BMI) are associated with dementia in midlife but not later in life (Fitzpatrick et al., 2009). This study also aimed to explore whether the association CVH and cognitive function is moderated by age. This analysis builds on prior research in Mexico by using an index of ideal levels of modifiable CVH factors as opposed to individual risk factors or indexes that include non-modifiable factors.

\section{Methods}

The current study used cross-sectional data from Wave 1 of the World Health Organization Study on Global Ageing and Adult Health (SAGE) undertaken in Mexico. This is an observational, longitudinal study representative of the general non-institutionalized adult population (18 years or older).

\section{Sample and procedure}

The methodology for SAGE has been published elsewhere (Kowal et al., 2012). In brief, the survey was conducted between 2009 and 2010. A stratified, multi-stage cluster sampling design was used to obtain a nationally representative sample. A probability proportion to size design was used to select clusters. Within each cluster, an enumeration of existing households was done to obtain an accurate measurement of size. As the focus of SAGE was on older adults, individuals aged $\geq 50$ years were oversampled. Interviews were conducted face-to-face at respondent's homes using Paper and Pencil Assisted Interview (PAPI). All the interviewers participated in a training course for the administration of the survey protocol. Quality control procedures were implemented during fieldwork (Üstun et al., 2005). Those participants who were not able to respond to the survey due to cognitive problems were administered a proxy interview. The individual response rate was $51 \%$. Sampling weights were generated to account for the sampling design. Post-stratification corrections were made to the weights to adjust for the population distribution obtained from the national census and for non-response.

Ethical approvals followed the ethical guidelines of the 1975 Declaration of Helsinki and were obtained from the Institutional Review Board of the National Institute of Public Health, Cuernavaca, Mexico. Study procedures for the secondary analysis were supervised by the University of Kansas Medical Center's Institutional Review Board as not involving human subjects research. Written informed consent from each participant was obtained by the National Institute of Public Health, Cuernavaca, Mexico. The SAGE dataset is publicly available at the WHO website (http://apps.who.int/healthinfo/ systems/surveydata/index.php/catalog/sage).

\section{Measures}

\section{Cognitive function}

Cognitive function was assessed using performance Spanish language measures of immediate and delayed verbal recall, verbal fluency, and forward and backward digit span. Verbal memory was tested using the Consortium to Establish a Registry for Alzheimer's disease verbal recall test, consisting of 
three repetitions of a ten-word list for immediate recall with scores ranging from 0 to 30 words recalled correctly, and then assessing the recall of these words after a 10-minute delay with scores ranging from 0 to 10 words recalled correctly (Morris et al., 1988). The verbal fluency test consisted of naming as many animals as possible in 1 minute with scores being the sum of different words correctly named (Morris et al., 1988). Digit span was used to assess memory capacity and executive function, using both forward and backward digit recall tests (Wechsler et al., 1997). The forward digit span version contained nine and the backward version eight series. Each series had two trials. The score in each digit span task was the series number in the longest series repeated without error in the first or second trial. An overall cognitive function score was calculated by averaging the standardized scores of each test. All cognitive tests have been validated in the Mexican population (Ostrosky-Solís et al., 1999; Wechsler, 2001; Tulsky and Zhu, 2003; Escobedo and Hollingworth, 2009; Sosa et al., 2009). The score in each digit span task was the series number in the longest series repeated without error in the first or second trial. An overall cognitive function score was calculated by averaging the standardized scores of each test.

\section{Cardiovascular health index}

We obtained the $\mathrm{CVH}$ indices following four of the seven criteria from the AHA definition (LloydJones et al., 2010). Full data on the remaining three criteria (fasting cholesterol, glucose, and diet) was not collected in the survey, and therefore was not included in the composite measures. All participants were asked whether they had ever used tobacco. Participants who had used tobacco were asked whether they currently used it daily, non-daily, or not at all. Those who reported former tobacco use were asked how old they were when they stopped using tobacco. Participants who had never smoked or quit more than 12 months before the survey were considered to have ideal smoking status in that criterion. Those who were current smokers or quit within the last 12 months were considered to have poor/intermediate smoking status. The Global Physical Activity Questionnaire (GPAQ) was used to measure the intensity, duration, and frequency of physical activity in three domains: occupational; transport-related; and discretionary or leisure time (Bull et al., 2009). The Spanish GPAQ has been validated among an almost fully Mexico-born sample in California (Hoos et al., 2012). The total time spent in physical activity during a typical week, including the number of days and intensity, were used to generate categories of ideal physical activity levels $(\geq 150$ minutes per week of moderate intensity, $\geq 75$ minutes per week of vigorous intensity, or a combination of both) and poor/intermediate levels (0-149 minutes per week of moderate intensity, 0-74 minutes per week of vigorous intensity or a combination of both). Weight and height were measured to calculate BMI, calculated as weight $/$ height $^{2}\left(\mathrm{~kg} / \mathrm{m}^{2}\right)$. Participants with a BMI $<25 \mathrm{~kg} / \mathrm{m}^{2}$ were considered to have ideal BMI levels and those with higher BMI were considered to have poor/immediate levels. Blood pressure was measured three times on the right arm of the seated respondent using a wrist blood pressure monitor. Out of three measurements, an average of the first two measurements was used as the blood pressure value in this analysis. Participants with systolic values $<120$ and diastolic values $<80 \mathrm{mmHg}$ were considered to have ideal blood pressure levels. Those with either systolic or diastolic blood pressure levels than ideal were considered to have poor/immediate levels. The four criteria for ideal $\mathrm{CVH}$ are in line with the Mexican national guidelines for tobacco use, physical activity, BMI, and blood pressure (Secretaría de Salud, 1999, 2009; Bonvecchio et al., 2015). Participants obtained a score of 1 if they met the ideal criterion for each component (smoking, physical activity, BMI, and blood pressure) and a 0 otherwise, with total score ranging from 0 to 4 points (Table 1). We used two definitions of $\mathrm{CVH}$, first as a continuous variable and second as a categorical variable with five groups $(0,1,2,3$, and $4)$. Secondary analyses examined the moderating effect of age (50-64 years and 65+ years) in the association between $\mathrm{CVH}$ and cognitive function and the association of cognition with each of the $\mathrm{CVH}$ components individually.

\section{Covariates}

Socio-demographic information included age (continuous), gender, years of education (continuous), wealth (continuous), and urbanicity (rural/urban). For wealth, a multi-step process was used where asset ownership was first converted to an asset ladder, and then the Bayesian post-estimation method was used to generate raw continuous income estimates. Urbanicity was defined consistently with the way the areas were legally proclaimed to be, including towns, cities and metropolitan areas (urban), commercial farms, small settlements, rural villages, and areas further away from towns and cities (rural).

\section{Statistical methods}

The analysis was restricted to participants aged $\geq 50$ years. Proxy respondent data was not included 
Table 1. Criteria for ideal or poor/intermediate levels of cardiovascular health of individual factors according to the index

\begin{tabular}{|c|c|c|}
\hline CVH INDEX & POOR/INTERMEDIATE & IDEAL \\
\hline & (0 points) & (1 point) \\
\hline Smoking status & Current smoker or quit $\leq 12$ months ago & Never smoker or quit $>12$ months ago \\
\hline Physical activity & $\begin{array}{l}0-149 \text { minute/week moderate intensity or } 0-74 \\
\text { minute/week vigorous intensity }\end{array}$ & $\begin{array}{l}\geq 150 \text { minute/week moderate intensity or } \geq 75 \\
\text { minute/week vigorous intensity }\end{array}$ \\
\hline Body mass index & $\geq 25 \mathrm{~kg} / \mathrm{m}^{2}$ & $<25 \mathrm{~kg} / \mathrm{m}^{2}$ \\
\hline Blood pressure & $\mathrm{SBP} \geq 120$ or $\mathrm{DPB} \geq 80 \mathrm{mmHg}$ & $\mathrm{SBP}<120$ and $\mathrm{DPB}<80 \mathrm{mmHg}$ \\
\hline
\end{tabular}

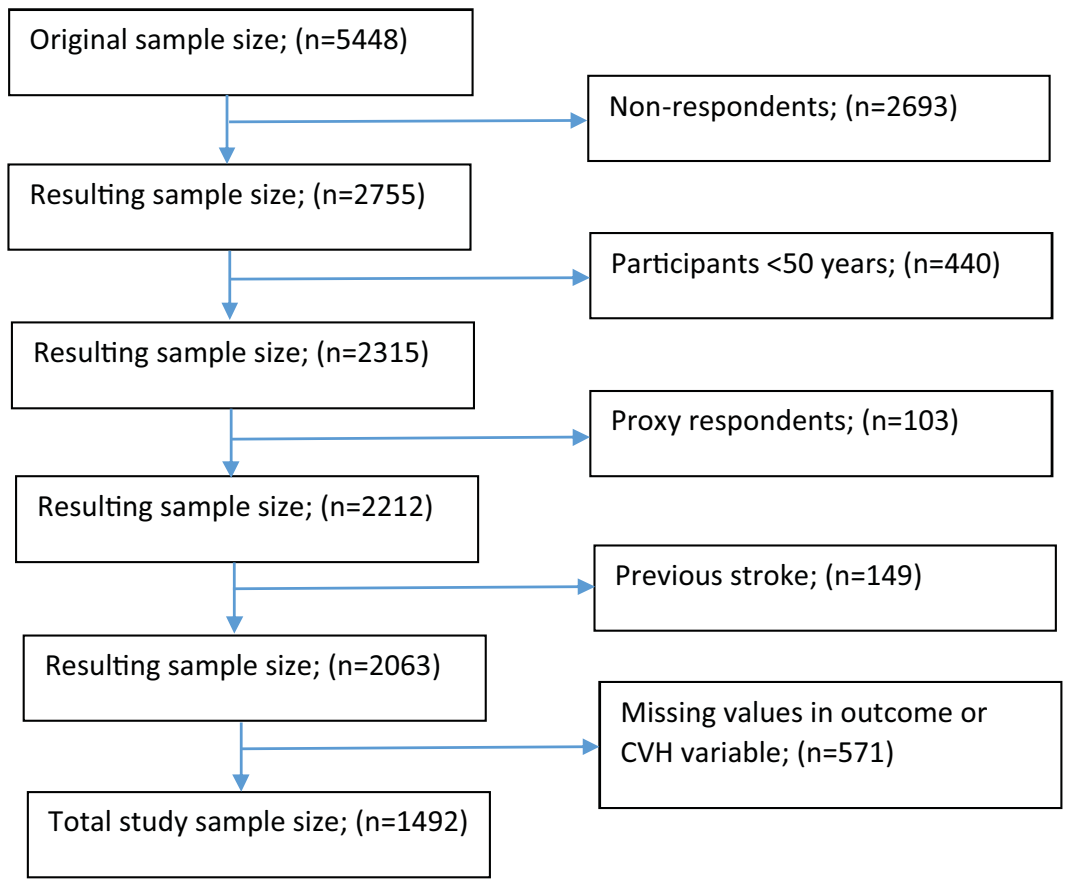

Figure 1. (Colour online) Sample flowchart and reasons for exclusion.

as they did not provide information on key variables. Participants with stroke assessed through either an algorithm or self-report of diagnosis were excluded from the sample as the association of $\mathrm{CVH}$ and stroke is well established (Dong et al., 2012; Kulshreshtha et al., 2013). Descriptive analyses included weighted percentages, unweighted frequencies, means, and standard errors. Models controlled for age, gender, education, wealth, and urbanicity. Interaction analysis was conducted to assess the moderating effect of age. Cross-sectional analyses were conducted using linear regression. The level for statistical significance for all analyses was set at $\mathrm{p}<0.05$. Complete case analysis was conducted. Figure 1 shows a flowchart with information on how the final sample was reached. Participants deleted based on missing values in CVH or cognitive function $(n=571)$ did not differ statistically from those not missing in age, gender, education, wealth, and urbanicity. All analyses were performed using SPSS version 22.0 using complex samples analysis (IBM Corp. Released, 2013).

\section{Results}

Among the 1,492 participants included in this analysis, the mean age was 61.6 years, ranging from 50 to 93 years and $53.6 \%$ were women. The average years of education was 5.1 and $21.6 \%$ lived in a rural setting (see Table 2). Socio-demographic factors were not associated with $\mathrm{CVH}$. CVH was worst (score 0) for $8.4 \%$, and best (score 4 ) for $2.2 \%$.

Table 3 shows the bivariate and multivariate linear regressions of global cognitive function with the continuous and categorical $\mathrm{CVH}$ indices and 
Table 2. Descriptive statistics of SAGE participants aged 50 years and over by cardiovascular health (CVH)

\begin{tabular}{|c|c|c|c|c|c|c|c|}
\hline & $\begin{array}{l}\text { TOTAL } \\
\text { SAMPLE; } \\
N=1,492\end{array}$ & $\begin{array}{l}\text { CVH } 0 ; \\
N=105 \\
(8.4 \%)\end{array}$ & $\begin{array}{l}\text { CVH } 1 ; \\
N=607 \\
(36.0 \%)\end{array}$ & $\begin{array}{l}\text { CVH } 2 ; \\
N=576 \\
(40.2 \%)\end{array}$ & $\begin{array}{l}\text { CVH } 3 ; \\
N=178 \\
(13.2 \%)\end{array}$ & $\begin{array}{l}\text { CVн } 4 ; \\
N=26 \\
(2.2 \%)\end{array}$ & $\begin{array}{l}P \\
\text { VALUE }\end{array}$ \\
\hline Age, mean (SE) & $61.6(1.0)$ & $61.7(1.2)$ & $61.5(1.4)$ & $61.9(1.3)$ & $61.8(3.0)$ & $57.0(2.7)$ & 0.85 \\
\hline Age, 50-64: $n(\%)$ & $669(69.1)$ & $41(70.9)$ & $273(70.3)$ & $260(65.5)$ & $81(73.7)$ & $14(82.4)$ & 0.89 \\
\hline Gender, women; $n(\%)$ & $936(53.6)$ & $40(42.3)$ & $396(44.8)$ & $372(58.5)$ & $115(75.0)$ & $13(25.3)$ & 0.06 \\
\hline Education, mean (SE) & $5.9(0.5)$ & $5.5(0.7)$ & $5.7(0.6)$ & $4.9(1.3)$ & $3.8(1.7)$ & $4.3(1.3)$ & 0.86 \\
\hline Wealth, mean (SE) & $0.1(0.0)$ & $0.1(0.1)$ & $0.1(0.1)$ & $0.1(0.1)$ & $0.1(0.1)$ & $0.1(0.1)$ & 0.79 \\
\hline Urbanicity, rural; $n(\%)$ & $403(21.6)$ & $18(6.3)$ & $153(28.4)$ & $166(18.8)$ & $58(14.2)$ & $8(64.3)$ & 0.80 \\
\hline
\end{tabular}

Table 3. Relationship of continuous and categorical indices of $\mathrm{CVH}$ and covariates with global cognitive function in the total sample and by age group

\begin{tabular}{|c|c|c|c|c|c|}
\hline & \multicolumn{3}{|c|}{ TOTAL SAMPLE } & \multirow{2}{*}{$\begin{array}{l}\text { AGES } 50-64 \\
\text { MULTIVARIATE }\end{array}$} & \multirow{2}{*}{$\begin{array}{l}\text { AGES } 65+ \\
\text { MULTIVARIATE }\end{array}$} \\
\hline & & MULTIVARIATE & MULTIVARIATE & & \\
\hline & & LINEAR & LINEAR & LINEAR & LINEAR \\
\hline & & REGRESSION & REGRESSION & REGRESSION & REGRESSION \\
\hline & BIVARIATE & WITH & WITH & WITH & WITH \\
\hline & LINEAR & CONTINUOUS & CATEGORICAL & CATEGORICAL & CATEGORICAL \\
\hline & REGRESSION & $\mathrm{CVH}^{\mathrm{b}}$ & $\mathrm{CVH}^{\mathrm{b}}$ & $\mathrm{CVH}^{\mathrm{c}}$ & $\mathrm{CVH}^{\mathrm{c}}$ \\
\hline $\begin{array}{l}\text { CVH } \\
\text { (continuous) }\end{array}$ & $0.00(-0.11: 0.11)$ & $0.02(-0.56: 0.10)$ & - & - & - \\
\hline \multicolumn{6}{|l|}{ CVH 4} \\
\hline CVH 3 & $-0.28(-0.73 ; 0.18)$ & & $-0.29(-0.64 ; 0.06)$ & $\begin{array}{l}-0.42 \\
(-0.83 ;-0.01)\end{array}$ & $-0.08(-0.63 ; 0.46)$ \\
\hline CVH 2 & $\begin{array}{l}-0.47 \\
(-0.83 ;-0.10)\end{array}$ & - & $\begin{array}{l}-0.56 \\
(-0.88 ;-0.25)\end{array}$ & $\begin{array}{l}-0.68 \\
(-1.04 ;-0.32)\end{array}$ & $-0.14(-0.69 ; 0.41)$ \\
\hline CVH 1 & $-0.31(-0.69 ; 0.07)$ & - & $\begin{array}{l}-0.39 \\
(-0.73 ;-0.05)\end{array}$ & $\begin{array}{l}-0.49 \\
(-0.85 ;-0.12)\end{array}$ & $-0.04(-0.60 ; 0.52)$ \\
\hline CVH 0 & $-0.31(-0.69 ; 0.07)$ & - & $\begin{array}{l}-0.41 \\
(-0.77 ;-0.05)\end{array}$ & $\begin{array}{l}-0.56 \\
(-0.97 ;-0.14)\end{array}$ & $-0.12(-0.69 ; 0.45)$ \\
\hline $\begin{array}{l}\text { Gender; women } \\
\text { (men REF) }\end{array}$ & $-0.11(-0.34 ; 0.12)$ & $-0.04(-0.23 ; 0.15)$ & $-0.02(-0.18 ; 0.13)$ & $0.01(-0.18 ; 0.20)$ & $-0.17(-0.37 ; 0.03)$ \\
\hline Age (per unit) & $\begin{array}{l}-0.03 \\
(-0.03 ;-0.02)\end{array}$ & $\begin{array}{l}-0.02 \\
(-0.27 ;-0.01)\end{array}$ & $\begin{array}{l}-0.02 \\
(-0.03 ;-0.01)\end{array}$ & - & - \\
\hline $\begin{array}{l}\text { Education (per } \\
\text { unit) }\end{array}$ & $0.05(0.04 ; 0.07)$ & $0.03(0.01 ; 0.05)$ & $0.03(0.02 ; 0.04)$ & $0.03(0.01 ; 0.05)$ & $0.04(0.02 ; 0.06)$ \\
\hline Wealth (per unit) & $0.74(0.61 ; 0.86)$ & $0.40(0.19 ; 0.62)$ & $0.39(0.21 ; 0.57)$ & $0.38(0.17 ; 0.58)$ & $0.35(0.15 ; 0.55)$ \\
\hline $\begin{array}{l}\text { Urbanicity; urban } \\
\text { (rural REF) }\end{array}$ & $0.36(0.20 ; 0.53)$ & $0.14(-0.04 ; 0.33)$ & $0.18(0.00 ; 0.35)$ & $0.25(0.03 ; 0.48)$ & $0.08(-0.11 ; 0.28)$ \\
\hline
\end{tabular}

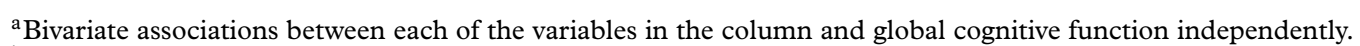

${ }^{b}$ Multivariate models control for all the gender, age, education, wealth, and urbanicity.

${ }^{\mathrm{c}}$ Multivariate models control for all the gender, education, wealth, and urbanicity. Data are $\beta$ 's (95\% CI) for global cognitive function $z$ scores. REF: reference category. Statistically significant associations at the 0.05 level are marked in bold.

covariates. The continuous $\mathrm{CVH}$ index was not associated with cognitive function in either the bivariate or multivariate models. Regarding the 0 4 categorical $\mathrm{CVH}$ index, in the bivariate linear regression, participants with the best levels of $\mathrm{CVH}$ (score 4) had cognitive function scores $0.47 S D$ higher than those with a score of $2(\mathrm{p}<0.05)$. After controlling for covariates, participants with best CVH (score 4) had higher cognitive function scores than those with a CVH score of $0(0.41 S D)$,
1 (0.39SD), and $2(0.56 S D ; \mathrm{p}<0.05$ for all differences). The interaction between $\mathrm{CVH}$ and age group was statistically significant $(p<0.001)$. The association between $\mathrm{CVH}$ and cognitive function was only present among participants $50-64$ years old in which best CVH (score 4) was associated with higher cognitive function scores compared to $\mathrm{CVH}$ scores of $0(0.56 S D), 1$ (0.49SD), 2 $(0.68 S D)$, and $3(0.42 S D ; \mathrm{p}<0.05$ for all differences). 
Table 4. Relationship of individual CVH factors with global cognitive function

\begin{tabular}{|c|c|c|}
\hline & $\begin{array}{l}\text { BIVARIATE LINEAR } \\
\text { REGRESSION }^{\mathrm{a}}\end{array}$ & $\begin{array}{l}\text { MULTIVARIATE LINEAR } \\
\text { REGRESSION }^{\text {b }}\end{array}$ \\
\hline \multicolumn{3}{|c|}{ Tobacco use (Ideal REF) } \\
\hline Poor/intermediate & $0.33(0.14 ; 0.52)$ & $0.17(0.01 ; 0.33)$ \\
\hline \multicolumn{3}{|c|}{ Physical activity (Ideal REF) } \\
\hline Poor/intermediate & $-0.17(-0.33 ;-0.01)$ & $-0.04(-0.168 ; 0.08)$ \\
\hline \multicolumn{3}{|c|}{ Body mass index (Ideal REF) } \\
\hline Poor/intermediate & $0.14(-0.08 ; 0.36)$ & $-0.01(-0.19 ; 0.19)$ \\
\hline \multicolumn{3}{|c|}{ Blood pressure (Ideal REF) } \\
\hline Poor/intermediate & $-0.29(-0.53 ;-0.04)$ & $-0.27(-0.49 ;-0.05)$ \\
\hline
\end{tabular}

Table 4 shows the bivariate and multivariate associations of global cognitive function with the individual $\mathrm{CVH}$ factors (smoking, exercise, $\mathrm{BMI}$, and blood pressure). Poor/intermediate levels of smoking were associated with $0.33 S D$ higher of cognitive function compared to ideal levels in bivariate and $0.17 S D$ in multivariate associations $(p<0.05$ each). In bivariate associations, ideal levels of exercise were associated with $0.17 S D$ higher of cognitive function than poor/intermediate levels, but the association disappeared after controlling for covariates. BMI was not associated with cognitive function in either model. Ideal blood pressure levels were associated with 0.29 $S D$ higher of cognitive function compared to poor/intermediate levels in the bivariate model and $0.27 S D$ in the multivariate model.

\section{Discussion}

This study has examined the cross-sectional association between an index of ideal levels of modifiable $\mathrm{CVH}$ factors and cognitive function among a representative sample of Mexican older adults. Findings suggest that $\mathrm{CVH}$ is positively but non-linearly associated with cognitive function in this population. In particular, participants with the best levels of $\mathrm{CVH}$ have higher cognitive function than those at lower levels. These associations are modified by age and are only present among people aged 50-64 years but not older.

The present study adds to the growing evidence that $\mathrm{CVH}$ is important for cognitive function (Reis et al., 2013; Crichton et al., 2014; Thacker et al., 2014; Gardener et al., 2016; González et al., 2016). The exclusion of participants with stroke suggests that there might be alternative vascular mechanisms for cognitive impairment other than stroke (Kulshreshtha et al., 2013). Contrary to findings from some previous studies using the AHA definition of $\mathrm{CVH}$, we found that only the best levels of $\mathrm{CVH}$ were associated with substantially higher cognitive function. This data contrasts with linear cross-sectional associations found among Latinos aged 45-74 years, and longitudinal associations in the general population aged 18-30 years in the USA (Reis et al., 2013; González et al., 2016). The results also contrast with a longitudinal study among Americans 45 years and older that found that cognitive impairment was highest for those with poor $\mathrm{CVH}$ but the same for those with intermediate and high levels of CVH (Thacker et al., 2014). In our study, however, $\mathrm{CVH}$ was measured using only four out of the seven AHA components of $\mathrm{CVH}$, making comparisons with other studies different. We also found that the association between the categorical index of $\mathrm{CVH}$ and cognitive function was stronger than associations with individual $\mathrm{CVH}$ components. This finding supports the idea that dementia prevention trials should focus on multiple cardiovascular risk reduction (Olanrewaju et al., 2015). These results are also in line with the AHA notion that prevention should not merely focus on preventing poor $\mathrm{CVH}$ levels but also promote optimal levels (Lloyd-Jones et al., 2010).

These results are the first attempt to examine the association between an AHA-like index of ideal levels of modifiable $\mathrm{CVH}$ factors and cognitive function in the Mexican population. The importance of using an AHA-like approach of $\mathrm{CVH}$ relies upon including biomarkers and behaviors that are modifiable and account for optimal levels of CVH (Lloyd-Jones et al., 2010). Therefore, the index used in the present study has more direct implications for health promotion and disease prevention than studies assessing the 
association with single factors, (Biessels et al., 2006; Cataldo et al., 2010; Bherer et al., 2013) examining solely poor levels of CVH (Biessels et al., 2006; Reitz et al., 2007) or including non-modifiable components (Unverzagt et al., 2011).

This study shows that the association between $\mathrm{CVH}$ and cognitive function is only present among participants $50-64$ years old. These findings are consistent with the literature as for example, BMI in midlife has been shown to be associated with dementia and cognitive function in later life, whereas BMI measured later in life has an inverse association with cognitive impairment (Fitzpatrick et al., 2009). Similarly, midlife hypertension has been shown to be an important modifiable risk factor for late life cognitive decline and dementia (Whitmer et al., 2005). However, the association in older ages remains unclear (Verghese et al., 2003; Kloppenborg et al., 2008). This study therefore adds to the evidence on the importance of timing and supports the idea that midlife may be a critical period for conducting $\mathrm{CVH}$ interventions to reduce dementia risk (Kloppenborg et al., 2008; Gorelick et al., 2011).

Findings from this study may also apply to many older adults living in the USA. In fact, a higher AHA CVH index score was crosssectionally associated with better cognitive function among USA Latinos of whom $33.4 \%$ were of Mexican descent (González et al., 2016). Currently, $34 \%$ of the 33.7 million Mexican Americans are Mexico-born (Gonzalez-Barrera and Lopez, 2013). Mexican Americans might share cultural and genetic characteristics related to $\mathrm{CVH}$ with the Mexican population, especially first generation ones. However, studies also suggest that the adaptation of Mexican Americans to the USA dominant culture might put them at a higher risk of dementia, as their risk of obesity, diabetes, sedentary lifestyle and smoking increases with the number of years lived in the USA (Goel et al., 2004; Caballero, 2005; Kondo et al., 2016). Generalizability of these findings to Mexican Americans may be threatened due to the Hispanic paradox in which there is a positive selection of immigrants from Mexico to the USA from the general population (Markides and Eschbach, 2005).

There are limitations to this study. First, the study lacked data on nutrition, glucose levels and cholesterol and therefore could not replicate the AHA definition of CVH (Lloyd-Jones et al., 2010). Differences found between this and other studies using the AHA definition of CVH may be related to the incomplete composite score. Second, the $\mathrm{CVH}$ index has not been previously validated in the Mexican population. Third, the assessment of $\mathrm{CVH}$ gives the same weight to the different domains, which might not represent their real contribution. Fourth, this study is cross-sectional, and therefore, causality cannot be inferred from the associations. In fact, associations such as the one between smoking and higher cognitive function have been shown to be an artifact of cross-sectional data, whereas longitudinal data shows associations in the opposite direction (Cataldo et al., 2010). Fifth, urbanicity was predefined according to the way the areas were legally proclaimed to be, which ignores the participants' urban or rural migrations. However, $90.6 \%$ of the sample had lived in the same locality either always or most of their adult lives adding little information to the predefined urbanicity variable. Finally, the lower response rate $(51 \%)$ may increase the risk of selection bias. Regarding potential public health implications, this study highlights the importance of optimal levels of $\mathrm{CVH}$, especially in midlife as a potential means to improve brain health among Mexican older adults. If results are confirmed with longitudinal data, this will mean that greater effort needs to be made to prevent cognitive decline by promoting optimal levels of $\mathrm{CVH}$ as a whole as the current prevalence of best $\mathrm{CVH}$ levels is $2.2 \%$. Comprehensive worksite wellness programs targeting weight, physical activity, blood pressure, and tobacco use might be optimal given that most Mexicans 50-64 years old are working and spend a significant part of their day at work. Workplace interventions have the potential to have economic and productivity benefits to employers in addition to health improvements (Baicker et al., 2010). These interventions will work best if paired with improvements in other evidence-based population $\mathrm{CVH}$ strategies, including media and educational campaigns, labeling and consumer information, taxation, subsidies, and other economic incentives, local environmental changes, direct restrictions, and mandates (Mozaffarian et al., 2012).

\section{Conclusion}

These findings add to the growing evidence that $\mathrm{CVH}$ is an important factor for cognitive health and is the first study in Mexico to address this association using an index of ideal levels of modifiable $\mathrm{CVH}$ factors. We found that the best levels of $\mathrm{CVH}$ were associated with higher cognitive function compared to other levels among stroke-free Mexican older adults. These results suggest that dementia-related policies in Mexico need to focus on optimizing $\mathrm{CVH}$ as a whole rather than simply preventing poor levels of isolated $\mathrm{CVH}$ factors. These findings also suggest that 
improving $\mathrm{CVH}$ at midlife might be more beneficial for cognitive function than later in life. Future research is needed as $\mathrm{CVH}$ might be a key to slow down the devastating health and financial dementia consequences affecting individuals, families, and societies in Mexico.

\section{Conflict of interest}

None.

\section{Description of authors' roles}

J. Perales was involved in the conception and design of the work and carried out the analysis. J. Perales, L. Hinton, J. Burns, and E. Vidoni were involved in the interpretation of data. The first version of the manuscript was written by J. Perales and was subsequently improved by L. Hinton, J. Burns, and E. Vidoni with important intellectual contributions. All authors have approved the final version.

\section{Acknowledgments}

JP is thankful to the SAGE teams in Mexico and the World Health Organization. He is also grateful for the chance to attend the Mexico capacity building sessions granted by his former team at the Parc Sanitari Sant Joan de Déu, Barcelona and funded by the European Commission and the Instituto Carlos III through the COURAGE in Europe project. This study was supported by the World Health Organization and the US National Institute on Aging through Interagency Agreements (OGHA 04034785; YA1323-08-CN0020; Y1-AG-1005-01) and through a research grant (R01-AG034479). Research reported in this publication was also supported by the National Institute on Aging of the National Institutes of Health under Award Number P30AG035982. The content is solely the responsibility of the authors and does not necessarily represent the official views of the National Institutes of Health.

\section{References}

Al Hazzouri, A. Z., Haan, M. N., Neuhaus, J. M., Pletcher, M., Peralta, C. A. and López, L. (2013). Cardiovascular risk score, cognitive decline, and dementia in older Mexican Americans: the role of sex and education. fournal of the American Heart Association, 2, e004978.

Baicker, K., Cutler, D. and Song, Z. (2010). Workplace wellness programs can generate savings. Health Affairs, 29, 304-311.
Bherer, L., Erickson, K. I. and Liu-Ambrose, T. (2013). A review of the effects of physical activity and exercise on cognitive and brain functions in older adults. Fournal of Aging Research, 2013. doi:10.1155/2013/657508.

Biessels, G. J., Staekenborg, S., Brunner, E., Brayne, C. and Scheltens, P. (2006). Risk of dementia in diabetes mellitus: a systematic review. The Lancet Neurology, 5, 64-74.

Bonvecchio, A., Fernández-Gaxiola, A., Plazas, M., Kaufer-Horwitz, M., Pérez, A. and Rivera, J. (2015). Nutrition and physical activity guidelines for overweight and obesity in the Mexican population [Guías alimentarias y de actividad física en contexto de sobrepeso y obesidad en la población mexicana]. Documento de Postura. Academia Nacional de Medicina (ANM). Intersistemas, México.

Bull, F. C., Maslin, T. S. and Armstrong, T. (2009). Global physical activity questionnaire (GPAQ): nine country reliability and validity study. Fournal of Physical Activity and Health, 6, 790-804.

Caballero, A. E. (2005). Diabetes in the Hispanic or Latino population: genes, environment, culture, and more. Current Diabetes Reports, 5, 217-225.

Cataldo, J. K., Prochaska, J. J. and Glantz, S. A. (2010). Cigarette smoking is a risk factor for Alzheimer's disease: an analysis controlling for tobacco industry affiliation. Fournal of Alzheimer's Disease, 19, 465-480.

Crichton, G. E., Elias, M. F., Davey, A. and Alkerwi, A. A. (2014). Cardiovascular health and cognitive function: the Maine-Syracuse longitudinal study. PLoS One, 9, e89317.

Dong, C., Rundek, T., Wright, C. B., Anwar, Z., Elkind, M. S. and Sacco, R. L. (2012). Ideal cardiovascular health predicts lower risks of myocardial infarction, stroke, and vascular death across whites, blacks and Hispanics: the northern Manhattan study. Circulation, 125, 2975-2984. doi:10.1161/CIRCULATIONAHA.111.081083.

Escobedo, P. S. and Hollingworth, L. (2009). Annotations on the use of the Mexican norms for the WAIS-III. Applied Neuropsychology, 16, 223-227.

Fitzpatrick, A. L. et al. (2009). Midlife and late-life obesity and the risk of dementia: cardiovascular health study. Archives of Neurology, 66, 336-342.

Gardener, H. et al. (2016). Ideal cardiovascular health and cognitive aging in the Northern Manhattan study. Fournal of the American Heart Association, 5, e002731.

Goel, M. S., Mccarthy, E. P., Phillips, R. S. and Wee, C. C. (2004). Obesity among US immigrant subgroups by duration of residence. $\mathcal{F A M A}, 292,2860-2867$.

Gonzalez-Barrera, A. and Lopez, M. H. (2013). A Demographic Portrait of Mexican-Origin Hispanics in the United States. Washington, DC: Pew Hispanic Center.

González, H. M. et al. (2016). Life's simple 7's cardiovascular health metrics are associated with Hispanic/Latino neurocognitive function: HCHS/ SOL results. Fournal of Alzheimer's Disease, 53, 955-965.

Gorelick, P. B. et al. (2011). Vascular contributions to cognitive impairment and dementia. Stroke, 42, 2672-2713.

Hoos, T., Espinoza, N., Marshall, S. and Arredondo, E. M. (2012). Validity of the global physical activity 
questionnaire (GPAQ) in adult Latinas. Fournal of Physical Activity and Health, 9, 698-705.

IBM Corp. Released (2013). IBM SPSS Statistics for Windows. Version 22.0. Armonk, NY: IBM Corp.

Instituto Nacional De Salud Pública (INSP) (2014). Study on Global Ageing and Adult Health (SAGE) Wave 1: Mexico National Report. London, UK: Instituto Nacional De Salud Pública (INSP).

Kloppenborg, R. P., Van Den Berg, E., Kappelle, L. J. and Biessels, G. J. (2008). Diabetes and other vascular risk factors for dementia: which factor matters most? A systematic review. European fournal of Pharmacology, 585, 97-108.

Kondo, K. K., Rossi, J. S., Schwartz, S. J., Zamboanga, B. L. and Scalf, C. D. (2016). Acculturation and cigarette smoking in Hispanic women: a meta-analysis. Fournal of Ethnicity in Substance Abuse, 15, 46-72.

Kowal, P. et al. (2012). Data resource profile: the World Health Organization Study on Global Ageing and Adult Health (SAGE). International fournal of Epidemiology, 41, 1639-1649.

Kulshreshtha, A. et al. (2013). Life's simple 7 and risk of incident stroke. Stroke, 44, 1909-1914.

Lloyd-Jones, D. M. et al. (2010). Defining and setting national goals for cardiovascular health promotion and disease reduction. Circulation, 121, 586-613.

Markides, K. S. and Eschbach, K. (2005). Aging, migration, and mortality: current status of research on the Hispanic paradox. The fournals of Gerontology: Series B: Psychological Sciences and Social Sciences, 60, S68-S75.

Mejia-Arango, S. and Gutierrez, L. M. (2011). Prevalence and incidence rates of dementia and cognitive impairment no dementia in the Mexican population: data from the Mexican Health and Aging Study. Fournal of Aging and Health, 23, 1050-1074.

Mejía-Arango, S., Miguel-Jaimes, A., Villa, A., Ruiz-Arregui, L. and Gutiérrez-Robledo, L. $M$. (2007). Cognitive impairment and associated factors in older adults in Mexico. Salud Pública de México, 49, S475-S481.

Morris, J. C., Mohs, R., Rogers, H., Fillenbaum, G. and Heyman, A. (1988). Consortium to establish a registry for Alzheimer's disease (CERAD) clinical and neuropsychological assessment of Alzheimer's disease. Psychopharmacology Bulletin, 24, 641-652.

Mozaffarian, D. et al. (2012). Population approaches to improve diet, physical activity, and smoking habits: a scientific statement from the American Heart Association. Circulation, 126, 1514-1563. doi:10.1161/CIR.0b013e318260a20b.

Olanrewaju, O., Clare, L., Barnes, L. and Brayne, C. (2015). A multimodal approach to dementia prevention: a report from the Cambridge Institute of Public Health. Alzheimer's \& Dementia: Translational Research \& Clinical Interventions, 1, 151-156.

Ordúñez, P., Silva, L. C., Rodríguez, M. P. and Robles, S. (2001). Prevalence estimates for hypertension in Latin America and the Caribbean: are they useful for surveillance? Revista Panamericana de Salud Pública, 10, 226-231.

Ostrosky-Solís, F., Ardila, A. and Rosselli, M. (1999). NEUROPSI: a brief neuropsychological test battery in Spanish with norms by age and educational level. fournal of the International Neuropsychological Society, 5, 413433.

Pearson, T. A. et al. (2013). American heart association guide for improving cardiovascular health at the community level, 2013 update. Circulation, 127, 1730-1753. doi:10.1161/CIR.0b013e31828f8a94.

Prince, M., Bryce, R., Albanese, E., Wimo, A., Ribeiro, W. and Ferri, C. P. (2013). The global prevalence of dementia: a systematic review and metaanalysis. Alzheimer's E Dementia, 9, 63-75. e2.

Reis, J. P. et al. (2013). Cardiovascular health through young adulthood and cognitive functioning in midlife. Annals of Neurology, 73, 170-179.

Reitz, C., Tang, M.-X., Manly, J., Mayeux, R. and Luchsinger, J. A. (2007). Hypertension and the risk of mild cognitive impairment. Archives of Neurology, 64, 1734-1740.

Secretaría de Salud (1999). Official Mexican Guidelines for the Prevention, Treatment and Control of Hypertension [Norma Oficial Mexicana, NOM-030-SSA2-1999, Para la Prevención, Tratamiento y Control de la Hipertensión Arterial]. Mexico City, Mexico: Secretaría de Salud.

Secretaría de Salud (2009). Official Mexican Guidelines for the Prevention, Treatment and Control of Addictions [Norma Oficial Mexicana, NOM-028-SSA2-2009, Para la Prevención, Tratamiento y Control de las Adicciones]. Mexico City, Mexico: Secretaría de Salud.

Shaw, J. E., Sicree, R. A. and Zimmet, P. Z. (2010). Global estimates of the prevalence of diabetes for 2010 and 2030. Diabetes Research and Clinical Practice, 87, 4-14.

Silvia, M.-A. and Clemente, Z.-G. (2011). Diabetes mellitus as a risk factor for dementia in the Mexicana elder population. Revista de Neurologia, 53, 397.

Sosa, A. L. et al. (2009). Population normative data for the 10/66 Dementia Research Group cognitive test battery from Latin America, India and China: a cross-sectional survey. BMC Neurology, 9, 48.

Thacker, E. L. et al. (2014). The American Heart Association life's simple 7 and incident cognitive impairment: the REasons for Geographic And Racial Differences in Stroke (REGARDS) study. Fournal of the American Heart Association, 3, e000635.

Tulsky, D. and Zhu, J. (2003). Escala Wechsler de Inteligencia para Adultos-III. Mexico, DF: El Manual Moderno.

Unverzagt, F. et al. (2011). Vascular risk factors and cognitive impairment in a stroke-free cohort. Neurology, 77, 1729-1736.

Üstun, T., Chatterji, S., Mechbal, A. and Murray, C. (2005). Quality assurance in surveys: standards, guidelines and procedures. In Household Sample Surveys in Developing and Transition Countries (pp. 199-230). New York, NY: United Nations.

Verghese, J., Lipton, R., Hall, C., Kuslansky, G. and Katz, M. (2003). Low blood pressure and the risk of dementia in very old individuals. Neurology, 61, 1667-1672. 
Wechsler, D. (2001). Escala Wechsler de Inteligencia Para Adultos-III (WAIS-III). Mexico, DF: El Manual Moderno.

Wechsler, D., Coalson, D. L. and Raiford, S. E. (1997). WAIS-III: Wechsler Adult Intelligence Scale. San Antonio, TX: Psychological Corporation.

Whitmer, R. A., Sidney, S., Selby, J., Johnston, S. C. and Yaffe, K. (2005). Midlife cardiovascular risk factors and risk of dementia in late life. Neurology, 64, 277-281.

World Health Organization (2012). Dementia: A Public Health Priority. Geneva, Switzerland: World Health Organization.
World Health Organization (2015). Country Statistics and Global Health Estimates. Mexico: World Health Organization.

World Obesity Federation (2017). World Obesity: Obesity Prevalence Worldwide-Adults. Available at: http://www.worldobesity.org/data/map/overviewadults\#country=CAN; last accessed 6 December 2017.

Yaffe, K., Haan, M., Blackwell, T., Cherkasova, E., Whitmer, R. A. and West, N. (2007). Metabolic syndrome and cognitive decline in elderly Latinos: findings from the Sacramento Area Latino study of aging study. Fournal of the American Geriatrics Society, 55, 758-762. 